\title{
INDÚSTRIA DE CELULOSE NO MUNICÍPIO DE MUCURI - BAHIA: PANORAMA DOS ASPECTOS SOCIOECONÔMICOS E USO DO SOLO
}

RESUMO: O município de Mucuri, localizado no Extremo Sul da Bahia, se destaca na silvicultura para a produção de celulose e desde o fim da década de 1980, abriga um complexo agroindustrial que integra o cultivo de eucalipto à unidade industrial, conduzindo um processo de especialização produtiva, modernização no campo e urbanização. Nesse sentido, presente estudo apresenta um panorama das transformações no uso e cobertura do solo e os aspectos socioeconômicos no município de Mucuri - Bahia. É apresentada a situação do território no período anterior e posterior à implantação da agroindústria, utilizando plataformas de geoprocessamento e bases de dados socioeconômicos. O estudo permite verificar o uso e cobertura do solo determinado predominantemente pela indústria de celulose, assim como a forte hegemonia do setor como determinante da estrutura socioeconômica local.

Palavras-Chave: Indústria de celulose; uso do solo; eucalipto; silvicultura.

\section{CELLULOSE INDUSTRY IN THE MUNICIPALITY OF MUCURI - BAHIA: PERSPECTIVE OF LAND USE AND SOCIOECONOMIC ASPECTS}

\begin{abstract}
The municipality of Mucuri, located in the extreme south of Bahia, stands out in silviculture for pulp production and since the end of the 1980s, it houses an agroindustrial complex that integrates eucalyptus cultivation with the industrial unit, leading to a process of productive specialization, modernization in the countryside and urbanization. In this sense, this study presents an overview of the transformations in land use and cover and the socioeconomic aspects in the municipality of Mucuri - Bahia. The situation of the territory in the period before and after the implementation of the agro-industry is presented, using geoprocessing platforms and socioeconomic databases. The study allows to verify the land use and cover determined predominantly by the cellulose industry, as well as the strong hegemony of the sector as a determinant of the local socioeconomic structure.
\end{abstract}

Keywords: cellulose industry; land use; eucalyptus; forestry.

\footnotetext{
${ }^{1}$ Mestrado em Desenvolvimento Regional e Meio Ambiente (UESC). Graduação em Ciências Econômicas (UESC). E-mail: rivanna.fm@gmail.com.
} 


\section{INTRODUÇÃO}

Desde o século XIX, com o avanço da modernização e do processo de expansão do capital no âmbito agrícola, o campo se tornou cenário de diversas mudanças, a nível nacional e regional, que por sua vez, reconfiguraram o uso e cobertura do solo. No Brasil, a partir da segunda metade do século XX, verifica-se a intensificação do processo de industrialização e dos investimentos em infraestrutura resultantes do cenário político e econômico nacional, que levaram a profundas transformações regionais (SILVA, 1998).

Nesse processo, tornou-se possível a expansão da fronteira agrícola nacional, além da transferência de diversas empresas, antes concentradas no Sudeste, para as demais regiões do país, a exemplo das indústrias do segmento de celulose, que passou por uma expansão a partir da década de 1970, associada às políticas públicas voltadas para a industrialização, a exemplo do Segundo Plano Nacional de Desenvolvimento. Assim, as primeiras empresas do segmento chegaram ao estado da Bahia, que passou a ganhar destaque nacional pelo desenvolvimento do agronegócio voltado à produção de eucalipto para a fabricação de celulose. O desenvolvimento do setor levou à reorganização socioeconômica, principalmente na região do Extremo Sul do Estado, que passou por importantes mudanças no uso e ocupação do solo (ALMEIDA, 2009).

Ao investigar esse processo de reorganização, o município de Mucuri se destaca, por suas origens históricas e características geográficas, assim como suas peculiaridades econômicas e sociais. Em 1992 entrou em operação a unidade industrial da Bahia Sul Celulose S.A no município, que desde a década de 1980 já cultivava eucalipto no território (SUZANO PAPEL E CELULOSE, 2015).

Desde então, o complexo agroindustrial passou a constituir grande parte do PIB municipal, chegando a mais de dois terços do valor adicionado por setor no ano de 2014, segundo o Instituto Brasileiro de Geografia e Estatística - IBGE (2016).

O processo de produção no setor de celulose e papel exige, por suas próprias particularidades, uma forte integração entre a silvicultura, como atividade desenvolvida no meio agrícola e a unidade industrial. No município, tal processo resultou imediatamente na mudança no uso do solo, quando extensas propriedades rurais passaram a pertencer ao capital industrial e os médios e grandes proprietários 
rurais do município aderiram à produção de eucalipto como principal atividade desenvolvida no campo a partir dos acordos de fomento florestal. Consequentemente, percebe-se a valorização das terras pelo capital atuante na região, concomitantemente à intensificação da concentração das terras (ALMEIDA, 2009).

Partindo dos aspectos tratados, objetivo do presente trabalho é analisar as mudanças no uso e cobertura do solo e a reorganização socioeconômica no município de Mucuri, a partir da instalação da agroindústria de celulose. A importância da pesquisa em questão reside na proposta de se estudar um processo de mudança na estrutura produtiva local com reflexo em aspectos socioeconômicos e de uso do solo, que se inter-relacionam, constituindo um relevante estudo de caráter interdisciplinar, com potencial para subsidiar a elaboração de políticas públicas para o município.

\section{MATERIAIS E MÉTODOS}

O presente estudo foi construído a partir de duas perspectivas: a anterior e a posterior ao desenvolvimento da cadeia produtiva de celulose, considerando como área de estudo o território de Mucuri, município localizado no Extremo Sul da Bahia (Figura 1). Seus limites são: o município baiano de Nova Viçosa ao norte, o Oceano Atlântico a leste e os estados do Espírito Santo ao sul e Minas Gerais a oeste.

Figura 1 - Delimitação da área de estudo: município de Mucuri (Bahia)

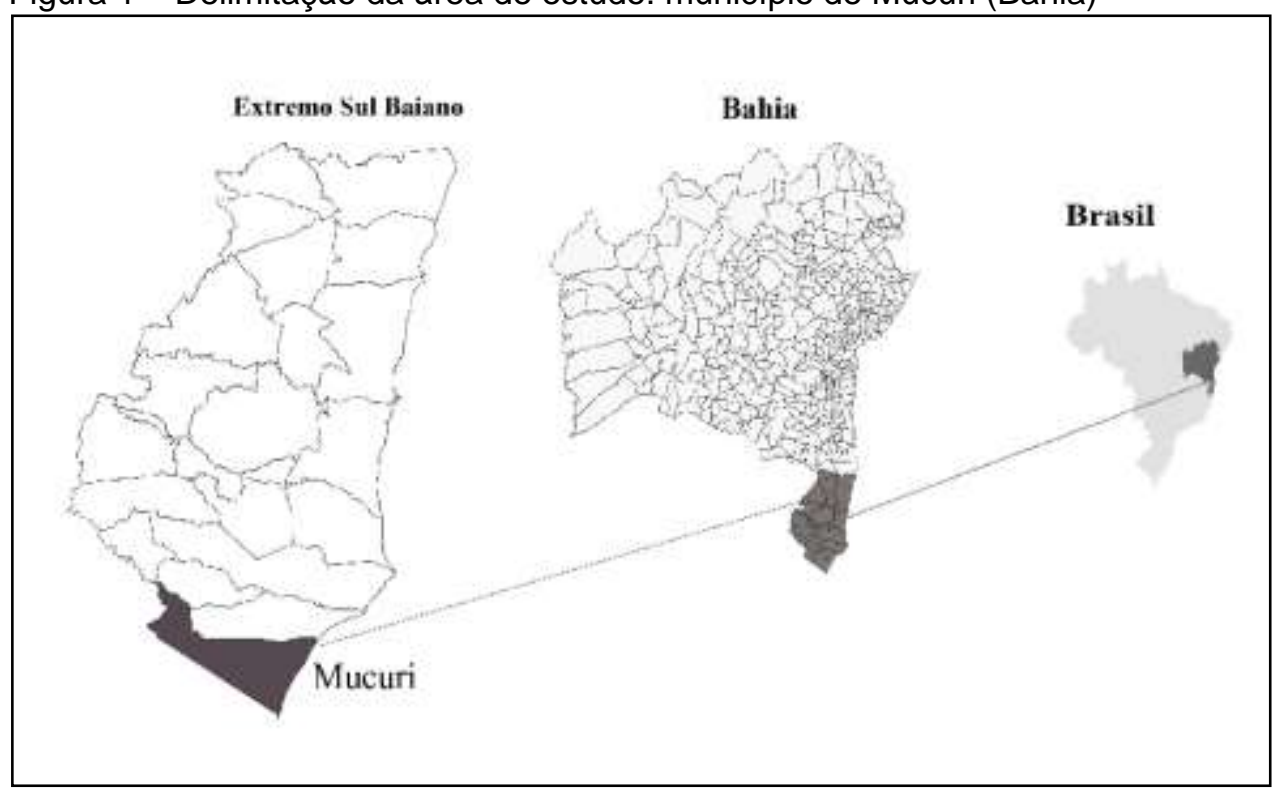

Fonte: Elaborada pela autora, a partir dos dados da Superintendência de Estudos Econômicos e Sociais da Bahia (2019). 
Para cumprir os objetivos propostos, os resultados são apresentados por meio de mapas, gráficos, figuras e tabelas. As principais fontes dos dados utilizados foram: Instituto Brasileiro de Geografia e Estatística (IBGE), Comissão Executiva do Plano da Lavoura Cacaueira (CEPLAC), Superintendência de estudos econômicos e sociais da Bahia (SEI), Atlas de Desenvolvimento Humano no Brasil (PNUD) e Projeto de Mapeamento Anual da Cobertura e Uso do Solo no Brasil (MapBiomas Coleção 4).

Realizou-se primeiramente uma pesquisa bibliográfica, documental e o levantamento de dados secundários, apresentando um panorama socioeconômico, histórico e geográfico do município, caracterizando o processo de ocupação do território até a década de 1980.

Posteriormente, foi construída a análise do uso e cobertura do solo, direcionada à compreensão da importância do complexo agroindustrial de produção de celulose na região. Assim, as transformações ocorridas em Mucuri são verificadas a partir da análise do período anterior à operação da agroindústria, a sua implantação e consolidação e a atual situação dos plantios de eucalipto para a produção de celulose no município.

\section{RESULTADOS}

\subsection{ASPECTOS GEOGRÁFICOS, PANORAMA HISTÓRICO E ECONÔMICO DO MUNICÍPIO}

Mucuri localiza-se no Extremo Sul da Bahia a $18^{\circ} 05^{\prime} 11^{\prime \prime}$ de Latitude e $39^{\circ} 33^{\prime}$ 03" de Longitude, em uma área de 1.786, 496 quilômetros quadrados, constituindo 0,3\% da área total do estado. Limita-se, ao norte com o município de Nova Viçosa, Ibirapuã e Lajedão; ao sul com o município capixaba de Pedro Canário; a oeste com os municípios mineiros de Nanuque e Serra dos Aimorés e a leste com o Oceano Atlântico (IBGE, 2016).

Atualmente, o município engloba os distritos de Ibiranhén, Taquarinha e Itabatã, além dos povoados de Nova Brasília, 31 de março, Belo Cruzeiro, Cruzelândia, Campo Formoso e São Jorge, totalizando 41.748 habitantes (IBGE CIDADES, 2019). 
A região apresenta uma temperatura média de $24^{\circ}$, sendo que a maior parte de sua área é composta por terrenos planos e arenosos ao nível do mar na Costa Atlântica e uma faixa de terreno silico-argiloso no interior, com algumas elevações, já nos limites com os estados do Espírito Santo e Minas Gerais (BGE CIDADES, 2019).

O Rio Mucuri é o mais importante recurso hídrico do Município. Nasce no leste de Minas Gerais e deságua no Oceano Atlântico, margeando o distrito sede de Mucuri. Ele é navegável em território baiano, entre a cachoeira de Santa Clara e a Foz, possuindo um curso de 195 quilômetros de extensão (DIAGNÓSTICO SOCIOECONÔMICO DA REGIÃO CACAUEIRA, 1976).

De acordo com a Companhia de Pesquisa de Recursos Minerais - CPRM (2010), além do Rio Mucuri e seus afluentes, a região possui áreas com alta porosidade e permeabilidade, favorecendo a formação de depósitos de água subterrânea, assim como a boa qualidade química da água, dada às proporções de areia e argila. O município apresenta solos bastante porosos, além de camadas de sedimentos de composições diversas, com alta capacidade de assimilação de material orgânico com boa retenção e fixação de nutrientes. Tais atributos do solo se apresentam no município pelo perfil do seu relevo, de natureza suave e contínua, resultando na facilidade para a escavação, com a utilização de maquinários e ferramentas simples.

Tendo como principal bioma a Mata Atlântica, a zona interiorana, próxima ao rio Mucuri possui vegetação típica. Na zona costeira, o estuário do Rio Mucuri apresenta grande biodiversidade, contando com ecossistemas variados, tais como matas ciliares, restingas, dunas e manguezais. Ao mesmo tempo, ocorrem locais naturalmente sujeitos à erosão e solapamentos pela ação marítima, principalmente na orla da área urbana, que demanda um constante trabalho de revitalização e controle ambiental (CPRM, 2010).

Com uma localização distinta, é o primeiro município nordestino para quem chega à Bahia pela região Sudeste e o último pela região Nordeste, fazendo fronteira com os estados de Minas Gerais a oeste, Espírito Santo ao sul. Até o século $\mathrm{XVI}$, a região que atualmente compreende a área do município de Mucuri era habitada por índios Pataxós, Abatires, Aimorés e os Botocudos (IBGE, 2016).

Com a colonização portuguesa, foram realizadas as primeiras expedições ao local, lideradas pelos bandeirantes Martim Carvalho e Antônio da Silva Guimarães, em busca de metais preciosos. No entanto, o fracasso dos garimpos, acabou dando 
lugar à exploração de pau-brasil e a produção de açúcar. Depois de quase dois séculos de exploração, as tribos indígenas ainda resistiam ao domínio dos portugueses, e em um cenário de constantes conflitos territoriais, as aldeias travaram em conjunto a expulsão dos colonos, atacando a capitania de Porto Seguro (IBGE, 2016).

Integrando as rotas marítimas do extremo sul baiano, o município contava com uma zona de aporte em um local próximo à foz do Rio Mucuri. Segundo a Prefeitura Municipal de Mucuri (2016), entre 1720 e 1730, povos alemães e suíços introduziram o cultivo de café na região, e pela existência da área de embarque e desembarque passaram a chamar o local de Porto Alegre, um dos primeiros aglomerados urbanos do Extremo Sul Baiano, habitada predominantemente por índios e europeus expatriados.

Assim, a vila de São José de Porto Alegre teve sua fundação no ano de 1769 , por Ordem Régia de Criação, conforme orientações da Coroa Portuguesa, passando a ser chamada de Mucuri somente em 1931. O nome advém do Rio Mucuri, principal recurso hídrico da região, que por sua vez tem seu nome em alusão a um tipo de madeira encontrada em abundância em suas margens (PREFEITURA MUNICIPAL DE MUCURI, 2016).

A partir de 1890, verifica-se a ocorrência das primeiras plantações de cacau em Mucuri, facilitada pelo acesso e escoamento de mercadorias pelo Rio Mucuri, assim como as características do clima, relevo e solo nas suas margens. Tais fatores contribuíram para a expansão da lavoura cacaueira na região, a partir no início do século $\mathrm{XX}$, tendo consideráveis extensões de terra dedicadas à atividade. $\mathrm{Na}$ década de 1930, o município já apresentava certo destaque na produção de cacau, sendo o décimo segundo entre os mais de vinte produtores na Bahia, em ordem de importância na contribuição total da safra anual de cacau (BONDAR, 1938).

Considerando que a viabilidade do cultivo de cacau era condicionada à extensão das propriedades rurais, havia uma forte tendência à concentração de terras. Assim, inicia-se um processo de acumulação de riqueza nas mãos dos pioneiros na produção da amêndoa, em sua maioria imigrantes europeus, que tiveram grande importância no processo de colonização do município (OTONI, 2002). 
Além do vale do Rio Mucuri, o município apresentava grande potencial hídrico, com diversas áreas alagáveis e um grande número de lagoas e riachos formados a partir de vias subterrâneas em terrenos permeáveis, constituindo uma região com potencial para exploração madeireira e culturas arbóreas de longa duração, assim como o cultivo de raízes, fruticultura e pastagens (BONDAR, 1938).

Bondar (1938) caracteriza as áreas do vale do Rio Mucuri ocupadas pelos cacauais como singulares, com copas de mais de dez metros de altura e troncos bastante sadios, chegando a mais de um metro de diâmetro, além de um nível de produtividade muito maior do que nos principais municípios produtores (llhéus e Itabuna). No entanto, faz algumas ressalvas quanto ao nível de atividade econômica local, ainda incipiente nesse período.

No fim da década de 1930, havia pouca mão de obra empregada e oferta de cacau ainda aquém da capacidade produtiva, pois as dificuldades de escoamento da produção acabavam tornando os preços do cacau mais baixos comparativamente a outras áreas nas mesmas condições naturais (vales do rio Pardo e Jequitinhonha).

Longe das áreas pluviais, a maior parte dos solos apresentava níveis de fertilidade relativamente baixos, que somados à dificuldade de acesso e transporte no município, realizado apenas pelas vias fluviais, algumas estradas sem pavimento, e pela ferrovia Bahia-Minas, representavam uma barreira ao processo de ocupação e diversificação no uso das terras mais distantes do rio (BONDAR, 1938).

Em 1950, Mucuri contava com 10.318 habitantes (5.247 homens e 5.071 mulheres). Deste total, 86\% residiam em áreas rurais e apenas 19\% de toda a população era alfabetizada. A sede do município era a cidade de Mucuri, na época a segunda menor população do estado, com 402 habitantes (IBGE, 1958).

Em 1955, a produção agrícola teve como sua maior parcela de contribuição o cacau, o coco e a cana de açúcar. Na pecuária, foram identificadas 8.000 cabeças de gado bovino, 25.000 suínos, 3.500 equinos, e 800 muares (animais bastante utilizados no transporte de cargas). Também se destacava a piscicultura e a extração vegetal, além da produção da farinha de mandioca como principal produto manufaturado; o comércio com as demais regiões era intermediado pela via portuária e ferroviária de Caravelas, baseado essencialmente na importação de bens de consumo e na exportação de cacau e madeiras; internamente, havia apenas nove estabelecimentos comerciais. Os meios de comunicação restringiam-se a 6 
agências de correios e telégrafos, e somente 52 residências contavam com energia elétrica (IBGE, 1958).

"Apesar de pioneiros terem se estabelecido [...] ao longo das principais linhas de drenagem com lavouras de milho, feijão, arroz, mandioca, cana-de-açúcar e café, [...] todos ao nível de subsistência, a ocupação humana do Agrossistema Mucuri era mínima" (DIAGNÓSTICO SOCIOECONÔMICO DA REGIÃO CACAUEIRA, 1976, p. 68).

A partir da década de 1960, inicia-se a extração, com a exploração das extensas áreas de florestas nativas, atividade que expandiu a ocupação das terras e continuou avançando até 1970, quando foi concluída a construção da BR-101. A produção de cacau continuava concentrada no vale do rio Mucuri e em terrenos alagáveis no interior do município (DIAGNÓSTICO SOCIOECONÔMICO DA REGIÃO CACAUEIRA, 1976).

O Diagnóstico Socioeconômico da Região Cacaueira (1976) divide os tipos de uso da terra durante a década de 1970: o primeiro pertence ao Agrossistema Cacaueiro, correspondente às áreas ao longo do Rio Mucuri (Subdistrito), com 140,6 km² de extensão e o segundo é denominado Agrossistema Pastoril, com 641,4 km² de extensão. Além dos cacaueiros e pastagens como principais usos do solo, haviam capoeiras com cultivos diversos, destinados à subsistência nas fazendas, e as áreas florestais, já bastante reduzidas em decorrência da exploração madeireira nas adjacências dos terrenos pastoris.

A atividade pesqueira também era praticada no município. Realizada artesanalmente, com o uso de pequenas embarcações, era em muitos casos, a única forma de subsistência das famílias que residiam em áreas mais próximas ao litoral, assim como as comunidades ribeirinhas ao longo do Rio Mucuri e seus afluentes. Os demais setores econômicos presentes no município tinham pouca importância no que se refere ao nível de dependência da população economicamente ativa e inativa, ou seja, a grande maioria da população do município era economicamente dependente da agricultura, pecuária, caça e pesca. A demanda por mão de obra era bastante associada à sazonalidade; em 1970, haviam 548 habitantes ocupados em trabalho permanente e 831 em ocupações temporárias. No tocante ao setor industrial considerando o mesmo período, o município se apresentava em um patamar ainda incipiente, se encontrando em 
relativo atraso quando comparado aos demais municípios da região do Extremo Sul da Bahia. No ano de 1973, Mucuri era responsável por apenas 0,05\% do total da produção industrial do Extremo Sul do estado (DIAGNÓSTICO SOCIOECONÔMICO DA REGIÃO CACAUEIRA, 1976).

Com relação à estrutura agrária do município, verifica-se durante a década de 1970 a ocorrência de estabelecimentos rurais ocupando cerca de 55\%. Tomando como base o padrão de módulos fiscais como unidade de medida estabelecida pelo Instituto Nacional de Colonização e Reforma Agrária (INCRA) para o município, no qual 1 módulo rural equivale a 35 hectares, verifica-se que quase metade dos estabelecimentos rurais da época se enquadrava na categoria de minifúndio (menos de $35 \mathrm{ha})$.

As pequenas e médias propriedades (com mais de 1 e menos de 15 módulos rurais) compreendiam aproximadamente 325 estabelecimentos. Na categoria de grande propriedade (com mais de 525 hectares - maiores que 15 módulos rurais) havia 36 estabelecimentos, equivalendo a 43\% de toda a área ocupada.

Apesar da produção expressiva da cacauicultura e da pecuária, somente após a construção do trecho Rio - Bahia da BR 101 e a BA 698, ligando a rodovia federal à sede do município, tornou-se efetivamente possível a integração socioeconômica local às regiões mais distantes. Até a década de 1970 eram frequentes os longos percursos a pé, além do transporte de mercadorias e pessoas por animais, e trocas diretas de produtos e serviços nas áreas mais afastadas do distrito sede. Em 1983, o município contava com 20.243 habitantes na zona rural e 2.284 na zona urbana. No mesmo período, despontava a atividade turística na região, que por suas riquezas naturais e culturais, passou a atrair visitantes nos períodos de alta temporada, que deram início ao fomento das atividades de comércio e serviços relacionadas ao turismo, com destaque para a venda de produtos regionais e hotelaria. (CIDADES DO CACAU, 1983).

Os serviços básicos de saúde (ambulatórios e farmácias), segurança (delegacia) e comunicação (telefone e correios), eram concentrados no distrito sede, não sendo suficientes para atender todo o município, principalmente nas áreas rurais, nas quais residia a maior parte da população. A educação oferecida era essencialmente o ensino primário, com 4.080 alunos matriculados em cinco escolas na sede do município, que contava com 100 professores na área urbana e 48 na zona rural (CIDADES DO CACAU, 1983). 
Em linhas gerais, até os anos de 1980, Mucuri não contava com uma atividade econômica sobrepujante. A pecuária e a cultura cacaueira eram responsáveis por boa parcela da renda gerada, mas naquele período se encontravam em declínio em decorrência da degradação do solo pelo emprego excessivo de pastagens, além da crise da lavoura cacaueira, levando a uma crescente desvalorização das terras do município.

\subsection{O USO DO SOLO NO MUNICÍPIO E MUDANÇAS SOCIOECONÔMICAS}

Em um contexto de desgaste da cultura cacaueira e da pecuária, a implantação do complexo agroindustrial de celulose e papel em Mucuri ocorreu a partir da entrada de capital privado e incentivo do Estado, dando lugar a um processo de modernização na esfera agrícola do município.

Entre o fim da década de 1980 até 1992, a unidade fabril foi construída, acompanhada da aquisição de extensas faixas de terra na região e do cultivo de eucalipto. A partir desse período são registradas mudanças consideráveis nas atividades desenvolvidas no meio rural, que podem ser observadas a partir da configuração do uso e cobertura do solo no município desde 1985 até 2018, conforme indicado no gráfico a seguir (Figura 2).

Gráfico 1 - Cobertura e uso do solo: formação florestal e agropecuária no município de Mucuri (19852018)

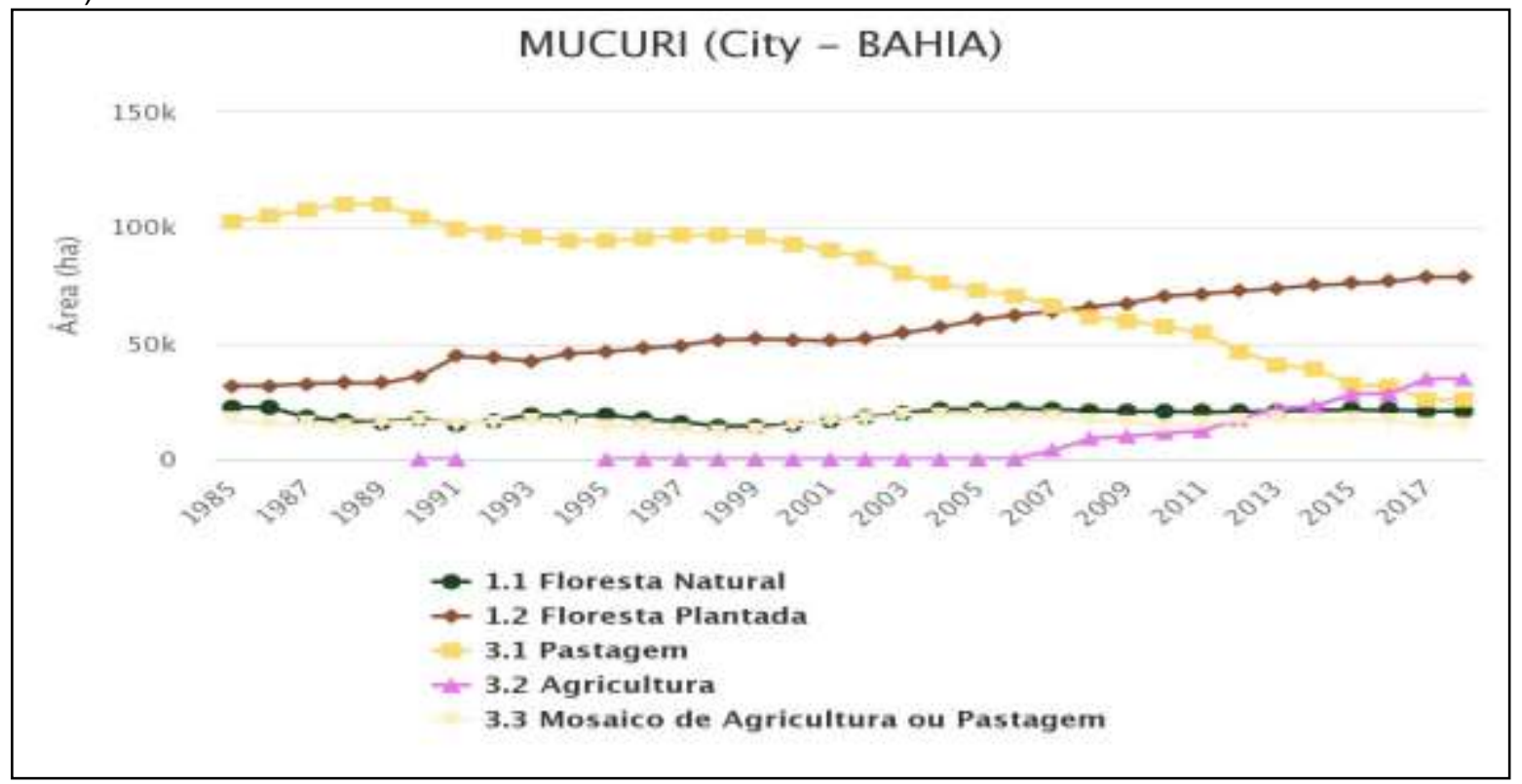

Fonte: Projeto MapBiomas - Coleção 4 da Série Anual de Mapas de Uso e Cobertura do Solo do Brasil (2018) 
O gráfico indica um forte declínio da atividade pecuária a partir do fim da década de 1990, enquanto as florestas plantadas passaram a ocupar cada vez mais espaço no território do município, superando as áreas de pastagens no ano de 2007. Esta tendência também é verificada quando se observa o efetivo dos rebanhos.

Entre 2005 e 2016, observa-se predominantemente a queda no número de animais criados, com destaque para os bovinos, que apresentaram uma queda de $39 \%$ durante o período. A única produção de origem animal que obteve um desempenho relevante foi o mel de abelha, que saltou de 9 para 98 toneladas entre 2005 em 2018 (IBGE, 2019).

Desde 2008, a apicultura vem se destacando como uma nova alternativa de geração renda no município, principalmente após parcerias estabelecidas entre apicultores e a agroindústria de celulose e papel, que produzem mel a partir da florada do eucalipto (SUZANO PAPEL E CELULOSE, 2016).

Todavia, além do aumento da produção de eucalipto, a Figura 2 indica que a diminuição das pastagens também está associada ao crescimento das áreas destinadas exclusivamente à agricultura. Até o ano de 2005, a atividade que era predominantemente realizada em conjunto com a pecuária, ganhou importância a partir de 2007, caracterizando um processo de especialização.

Tal processo é verificado quando se considera a queda na produção dos cultivos diversificados (banana, cacau em amêndoa, laranja e feijão), acompanhado da preponderância da produção da cana-de-açúcar e da ampliação da capacidade produtiva no campo indicada pelo aumento da quantidade produzida em relação à área cultivada (IBGE, 2019).

Além das modificações na produção na agricultura e pecuária, as mudanças no uso do solo percebidas no município estão associadas principalmente à agroindústria de celulose, ocasionadas pela ocupação de grandes áreas para a silvicultura, iniciada em terras adquiridas pela empresa na fase de implantação do complexo agroindustrial no fim da década de 1980, se expandindo com o passar dos anos, conforme descrito a seguir (Tabela 1). 
Tabela 1 - Produtos da silvicultura: madeira em tora para papel e celulose

\begin{tabular}{lcc}
\hline Ano & Quantidade produzida $\left(\mathbf{m}^{3}\right)$ & Valor da Produção $(\mathbf{R} \$)$ \\
\hline 2005 & 4.456 .540 & 244.218 .000 \\
2006 & 1.805 .429 & 100.237 .000 \\
2007 & 2.490 .019 & 169.321 .000 \\
2008 & 1.728 .489 & 73.011 .000 \\
2009 & 2.812 .156 & 112.486 .000 \\
2010 & 2.050 .254 & 112.969 .000 \\
2011 & 1.881 .008 & 140.831 .000 \\
2012 & 2.162 .383 & 170.028 .000 \\
2013 & 902.941 & 93.581 .000 \\
2014 & 1.361 .040 & 39.103 .000 \\
2015 & 1.210 .418 & 102.268 .000 \\
2016 & 1.876 .225 & 177.491 .000 \\
2017 & 1.803 .776 & 106.675 .000 \\
\hline
\end{tabular}

Fonte: Elaborada pela autora a partir de dados dos dados do IBGE (2019).

Nos últimos anos, além da madeira própria, o abastecimento fabril também conta com um considerável número de contratos de compra de eucalipto produzido pelos proprietários rurais da região, que compõem o projeto de fomento florestal da agroindústria. No entanto, mesmo com os grandes volumes gerados pela silvicultura em todo o período, a produção de eucalipto no município está sujeita às oscilações, atribuídas principalmente às variações no preço da madeira e da celulose de mercado.

A atuação da indústria de celulose também influencia na decisão dos pequenos produtores, que mesmo não tendo vínculo com a produção de eucalipto, percebem a valorização das suas terras. Quando inseridos em espaços cercados pela monocultura e frente às diversas situações de dificuldade associadas à falta de incentivos na produção agropecuária, os proprietários passam a optar pela venda das suas terras aos grandes produtores de eucalipto, que as incorporam na atividade madeireira. A Figura 3 sintetiza as transformações no uso e cobertura do solo em Mucuri, na qual se observa o predomínio das florestas plantadas para a indústria de celulose em ralação aos demais tipos de uso.

Os mapas indicam a contundente ocupação do território com florestas plantadas, intensificada entre 2000 e 2018, assim como a expansão das áreas de cultura anual e perene e a retração das áreas de pastagens. As áreas de formação florestal se concentram às margens do Rio Mucuri e em algumas regiões com plantios de eucalipto em mosaico. 
Figura 2 - Mapas de uso e cobertura do solo em Mucuri: anos de 1985, 2000 e 2018
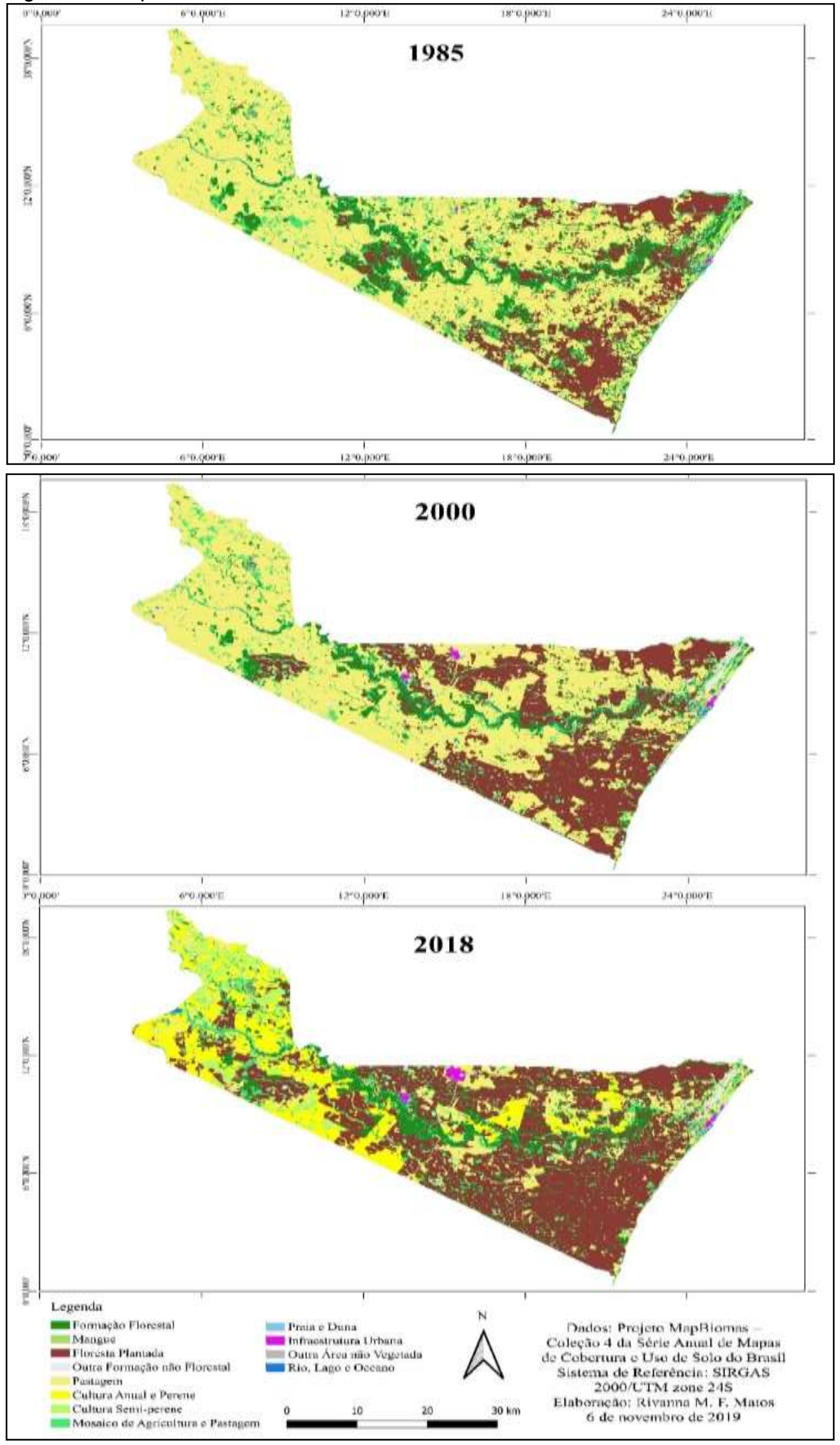

Fonte: Elaborado pela autora a partir dos dados do MapBiomas (Coleção 4). 
As plantações de eucalipto são divididas em sete setores, sendo que cada um é cultivado anualmente. Assim, como o eucalipto é colhido após sete anos, o plantio e o corte da madeira são realizados de forma constante e rotativa. (SUZANO PAPEL E CELULOSE, 2008).

De acordo com o IBGE (2016), a produção de madeira de eucalipto em Mucuri resultou em mais de $R \$ 100$ milhões em 2015, quando foram registrados 56.945 hectares de área plantada. Considerando que a área total do município corresponde a 178.650 hectares, pode-se inferir que atualmente cerca de 1/3 de todo o território mucuriense está ocupado com as florestas plantadas para a indústria de celulose.

Outra transformação percebida no município foi a expansão das áreas de infraestrutura urbana, ocasionada principalmente pelo processo de urbanização conduzido pela agroindústria, que intensificou o êxodo rural e atraiu trabalhadores imigrantes. Até 1980, a população do município apresentava uma evolução negativa, passando a crescer mais que o dobro entre 1991 e 2010, como mostra a Tabela 2.

Tabela 2 - População urbana e rural de Mucuri entre 1970 e 2010

\begin{tabular}{|c|c|c|c|c|c|}
\hline \multirow[t]{2}{*}{ Ano } & \multicolumn{2}{|c|}{ Urbana } & \multicolumn{2}{|c|}{ Rural } & \multirow[t]{2}{*}{ Total } \\
\hline & $\mathrm{N}^{\circ}$ habitantes & $\%$ & $\mathrm{~N}^{\circ}$ habitantes & $\%$ & \\
\hline 1970 & 2.262 & $13,49 \%$ & 14.504 & $86,51 \%$ & 16.766 \\
\hline 1980 & 2.827 & $18,67 \%$ & 12.317 & $81,33 \%$ & 15.144 \\
\hline 1991 & 4.810 & $27,32 \%$ & 12.796 & $72,68 \%$ & 17.606 \\
\hline 2000 & 18.685 & $66,58 \%$ & 9.377 & $33,42 \%$ & 28.062 \\
\hline 2010 & 27.492 & $76,31 \%$ & 8.534 & $23,69 \%$ & 36.026 \\
\hline
\end{tabular}

Fonte: Censo IBGE (2010).

O crescimento populacional no período foi acompanhado pela inversão na proporção de residentes. Até 1990, predominavam os domiciliados nas áreas rurais; atualmente, quase $80 \%$ da população de Mucuri se concentra em áreas urbanas. Acompanhando o processo de urbanização, aumentaram os esforços do poder público na ampliação da oferta de bens e serviços públicos à população que se expandia de maneira substancial. A atuação do capital industrial, somada à atuação política no município, reverberaram em toda a estrutura socioeconômica local. Em 2006, Mucuri se destacou entre os municípios baianos com altos índices socioeconômicos, como indicado na Tabela 3. 
Tabela 3 - Indicadores municipais no ano de 2006 - Mucuri

\begin{tabular}{lcc}
\hline \multicolumn{1}{c}{ Índice } & Valor & Ranking estadual \\
\hline Índice de Desenvolvimento Econômico & 5142,29 & $10^{\circ}$ \\
Índice de Desenvolvimento Social & 5093,81 & $24^{\circ}$ \\
Índice de Infraestrutura & 5227,04 & $7^{\circ}$ \\
Índice de Produto Municipal & 5032,52 & $21^{\circ}$ \\
Índice de Qualificação de Mão-de-Obra & 5169,25 & $10^{\circ}$ \\
Índice de Renda Média dos Chefes de Família & 5304,29 & $5^{\circ}$ \\
\hline
\end{tabular}

Fonte: Superintendência de estudos econômicos e sociais da Bahia - SEI (2019)

De acordo com o Atlas de Desenvolvimento Humano no Brasil (2013), o Índice de Desenvolvimento Humano Municipal (IDHM), que leva em conta fatores como a longevidade, renda e educação evoluiu positivamente após a implantação do complexo agroindustrial de celulose. Com um indicador de 0,275 em 1991, muito abaixo da média nacional, obteve uma melhora relevante, atingindo 0,665 em 2010.

Verifica-se que o município apresenta níveis de distribuição de renda acima da média nacional; todavia, mesmo com uma evolução positiva no IDHM, apresenta taxas de pobreza maiores que a nacional, como indicado na Tabela 4.

Tabela 4 - Renda e pobreza no município de Mucuri (2010)

\begin{tabular}{lcc}
\hline \multicolumn{1}{c}{ Indicadores } & Brasil & Mucuri \\
\hline Percentual de extremamente pobres & 6,62 & 8,52 \\
Percentual de pobres & 15,2 & 22,95 \\
Percentual de vulneráveis à pobreza & 32,56 & 44,93 \\
Percentual da renda apropriada pelos 80\% mais pobres & 36,6 & 38,3 \\
Percentual da renda apropriada pelos 20\% mais ricos & 63,4 & 61,7 \\
\hline
\end{tabular}

Fonte: Atlas do Desenvolvimento Humano no Brasil (2019)

Considerando que o plantio de eucalipto integrado à produção de celulose compõe o valor adicionado pela indústria, verifica-se a forte dependência deste setor na composição da renda em Mucuri, a julgar pelo valor adicionado por cada setor produtivo ao Produto Interno Bruto Municipal no período entre 2002 e 2014 (Figura 4). 
Gráfico 2 -Valor Adicionado Bruto Municipal, por setor, Mucuri (2002 e 2014)

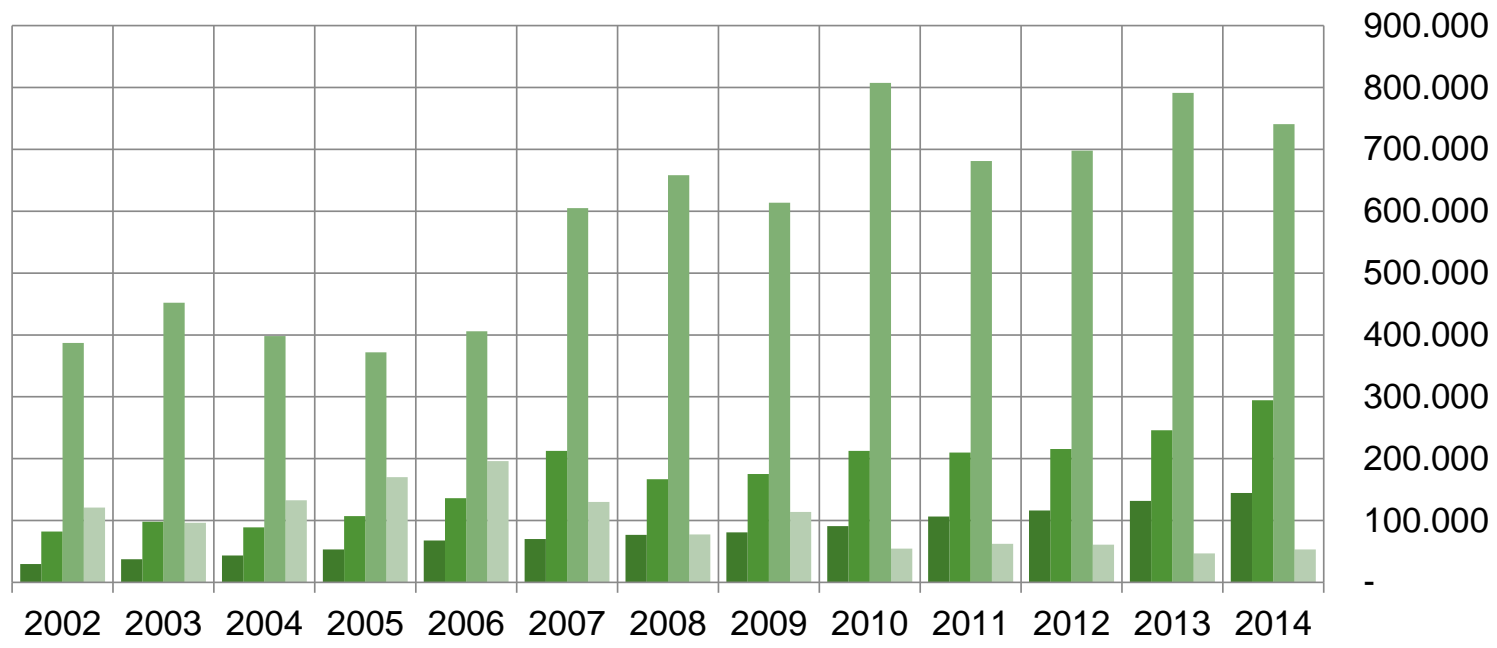

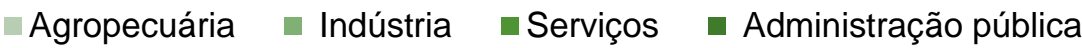

Fonte: Elaborado pela autora a partir de dados do IBGE (2019).

O gráfico indica que a atuação da administração pública e o setor de serviços também apresentou expansão, e apenas a agropecuária apresentou uma queda na composição do produto municipal. Ao mesmo tempo, observa-se que a produção da indústria de celulose está condicionada ao preço da madeira de eucalipto e da celulose de mercado, o que ocasiona as oscilações no valor adicionado pela indústria ao longo do período.

Em sintese, este estudo permitiu verificar que desde ao fim da década de 1980, a modernização da produção agrícola e processo de expansão do capital industrial reconfigurou o uso e cobertura do solo e a estrutura socioeconômica na qual o município de Mucuri estava firmado. Em trinta anos, Mucuri teve a sua população triplicada e transferida para as áreas urbanas; atualmente, o setor industrial é responsável por mais da metade da riqueza gerada em todo o município.

No entanto, o alto valor adicionado pela indústria ao produto municipal só é possível graças a atividade desenvolvida no campo, ou seja, a produção de eucalipto, que só tem representatividade em termos de agregação de valor ao produto (celulose) quando associada ao capital industrial. A riqueza gerada no município reflete em altos índices socioeconômicos e alimenta o processo de expansão do capital na região. 


\section{CONCLUSÕES}

Em linhas gerais, é inegável o crescimento econômico no município, assim como a evolução positiva na sua estrutura socioeconômica após a implantação da agroindústria de celulose, haja vista os altos índices observados, tais como o desempenho econômico, infraestrutura, qualificação, emprego e renda.

Percebe-se claramente a atuação da indústria de celulose como fator de acréscimo ao desenvolvimento econômico do município. Contudo, a própria magnitude do capital que vem sendo empregado na região, considerando a sua área e população relativamente pequena, implica na hegemonia do setor como o padrão econômico do município. Mucuri é dependente das decisões de uma única firma, o que o torna suscetível às incertezas do segmento industrial, que por sua vez, tem o seu desempenho sujeito ao mercado financeiro e às flutuações do comércio internacional.

Dessa maneira, o município carece de maiores incentivos por parte do poder público no sentido promover o desenvolvimento socioeconômico por meio da diversificação produtiva local, atraindo investimentos advindos de outros setores. $\mathrm{Na}$ agropecuária, os incentivos devem se direcionar à pluriatividade na agricultura, muitas vezes dificultada pela falta de recursos dos pequenos produtores para a compra de insumos agrícolas, além de técnicas mais modernas para a produção pecuária.

Também há espaço para novas indústrias no município, principalmente para as de menor porte, direcionadas ao beneficiamento de produtos da agropecuária local, que irão apresentar um valor agregado. Já o comércio e os serviços, apesar de apresentarem uma evolução positiva no valor adicionado ao produto municipal nos últimos anos, constituem o setor que apresenta as maiores possibilidades de expansão, se as políticas públicas para o desenvolvimento município forem intensificadas.

\section{REFERÊNCIAS}

ALMEIDA, T. M, de. Cultivo de eucalipto no extremo Sul da Bahia: Modificações no uso da terra e socioeconômicas. Ilhéus: UESC, 2009, 132 p. 
ATLAS DO DESENVOLVIMENTO HUMANO NO BRASIL. Perfil Municipal.

Disponível em: < http://www.atlasbrasil.org.br/2013/pt/perfil/> Acesso em: 06 mai. 2019.

BONDAR, G. Acultura do cacao na Bahia. Instituto de Cacao da Bahia. Boletim Technico n¹. São Paulo, 1938.

COMISSÃO EXECUTIVA DO PLANO DA LAVOURA CACAUEIRA (CEPLAC). Cidades do cacau. Mucuri. 1983.

COMPANHIA DE PESQUISA DOS RECURSOS MINERAIS (CPRM) - SERVIÇO GEOLÓGICO DO BRASIL. Ministério de Minas e Energia. Geodiversidade do Estado da Bahia.Programa Geologia do Brasil: Levantamento da Geodiversidade. Salvador, 2010.

DIAGNÓSTICO SOCIOECONÔMICO DA REGIÃO CACAUEIRA. Aspectos da atividade pesqueira. IICA/CEPLAC. In: FERREIRA, O. v. 9. Rio de Janeiro, 1976.

DIAGNÓSTICO SOCIOECONÔMICO DA REGIÃO CACAUEIRA. Dinâmica do uso da terra. IICA/CEPLAC. In: LEITE, J. O. v. 3. Rio de Janeiro, 1976.

DIAGNÓSTICO SOCIOECONÔMICO DA REGIÃO CACAUEIRA. Mão-de-obra e elementos de relações de produção. IICA/CEPLAC. In: REIS, A. M. B. dos. v. 11. Rio de Janeiro, 1976.

DIAGNÓSTICO SOCIOECONÔMICO DA REGIÃO CACAUEIRA. Recursos hídricos. IICA/CEPLAC. In: ROCHA FILHO, C. A. v. 5. Rio de Janeiro, 1976.

SILVA, J. G. A nova dinâmica da agricultura brasileira. 2 ed. São Paulo: Unicamp. Instituto de Economia, 1998.

INSTITUTO BRASILEIRO DE GEOGRAFIA E ESTATÍSTICA (IBGE). Biblioteca. Mucuri - Bahia: Histórico. Disponível em:<http://biblioteca.ibge.gov.br/visualizacao/dtbs/bahia/mucuri.pdf> Acesso em: 9 mai.2016

INSTITUTO BRASILEIRO DE GEOGRAFIA E ESTATÍSTICA (IBGE). Sistema de Recuperação Automática de Dados (SIDRA). Disponível em:<https://sidra.ibge.gov.br/home/pms/brasil> Acesso em: 18 abr. 2019.

INSTITUTO BRASILEIRO DE GEOGRAFIA E ESTATÍSTICA (IBGE). Municípios brasileiros. Vol. 21, Rio de Janeiro, 1958.

MUCURI (Muncípio). Prefeitura Municipal de Mucuri. Dados gerais. Disponível em: <http://www.mucuri.ba.gov.br/cidade/dados-gerais/> Acesso em: 6 mai. 2016.

MUCURI (Muncípio). Prefeitura Municipal de Mucuri. História. Disponível em: <http://www.mucuri.ba.gov.br/cidade/historia/> Acesso em: 6 mai. 2016 
OTONI, T. Notícia sobre os selvagens do Mucuri. In: DUARTE, R. H. (Org.). Belo Horizonte: UFMG, 2002.

PROJETO MAPBIOMAS - Coleção 4 da Série Anual de Mapas de Cobertura e Uso de Solo do Brasil, disponível em <http://plataforma.mapbiomas.org/map\#coverage> Acesso em: 22 mar 2019.

PROJETO MAPBIOMAS - Coleção 4 da Série Anual de Mapas de Cobertura e Uso de Solo do Brasil, disponível em < http://plataforma.mapbiomas.org/stats $>$ Acesso em: 22 mar 2019.

SUPERINTENDÊNCIA DE ESTUDOS ECONÔMICOS E SOCIAIS DA BAHIA (SEI). Informações Municipais. Disponível em:

<http://www.sei.ba.gov.br/index.php?option=com_wrapper\&view=wrapper\&ltemid=72 9> Acesso em: 10 mar. 2016

SUZANO PAPEL E CELULOSE (Empresa). Institucional. Disponível em: <http://www.suzano.com.br/portal/suzano-papel-e-celulose-1.htm> . Acesso em: 20 mar 2019.

SUZANO PAPEL E CELULOSE (Empresa). Eucaliptocultura e desenvolvimento socioambiental. $2 \mathrm{Ed}, 2008$. Disponível em: < http://www.suzano.com.br/wpcontent/uploads/2016/09/book_eucaliptocultura.pdf> Acesso em 20 dez 2018.

SUZANO PAPEL E CELULOSE (Empresa). Resumo público: plano de manejo florestal. Suzano Unidade Florestal Bahia. Disponível em:

$<$ http://www.suzano.com.br/wp-

content/uploads/2016/10/sumario_2013ba_corrigido_parte1-1.pdf > Acesso em: 30 jun 2019. 